\title{
Setting the scene for paramedics in general practice: what can we expect?
}

\author{
Kamal R. Mahtani \\ GP \& Deputy Director, Centre for Evidence Based Medicine, Nuffield Department of Primary \\ Care Health Sciences, University of Oxford
}

\section{Georgette Eaton}

Senior Lecturer Paramedic Science, Department of Psychology, Health and Professional Development, Faculty of Health and Life Science Oxford Brookes University

\section{Matthew Catterall}

Principal Lecturer \& Programme Lead (Paramedic Practice), Department of Psychology, Health and Professional Development, Faculty of Health and Life Science Oxford Brookes University

\author{
Alice Ridley \\ Specialist Paramedic, The Doctors House, Marlow Medical Group, Buckinghamshire \\ Address for correspondence \\ Kamal R. Mahtani, Centre for Evidence Based Medicine, Nuffield Department of Primary Care \\ Health Sciences, University of Oxford \\ Email: kamal.mahtani@phc.ox.ac.uk
}

Word count: 1015 (excluding tables) 
Primary care services in England may be reaching saturation point. Demands to see a GP or practice nurse have increased substantially. Clinical complexity has also increased; patients are living longer, but with more multimorbidity.[1] These demands are mirrored by a decline in the GP workforce, despite political pledges to reverse this.[2]

New strategies are needed to tackle the current pressures in general practice and reduce the risks of harm to patients. The NHS England GP Forward View advocates investing and developing new models of care, including expansion of a multidisciplinary, integrated primary care team.[3] These recommendations reflect the findings of the Primary Care Workforce Commission, who highlighted the potential roles for clinical pharmacists, physician associates, healthcare assistants and physiotherapists, which many general practices are now making greater use of.[4-6]

The Commission also recommended that general practices should consider more opportunities to use the skills of paramedics in primary care. Specific roles may include running clinics, triaging and managing minor illnesses, as well as provide continuity for patients with complex health needs. Further roles may include assessment and management of requests for sameday urgent home visits, as well as regular visits to homebound patients with long-term conditions. The commision highlighted that these innovative roles should be subject to further evaluation. Nevertheless, historical and current perspectives allow us to model how the role could be fully used.

\section{Paramedics as primary-care generalists}

Paramedics have a track record in providing flexible and innovative ways of delivering extended clinical care. Such developments have predominantly centred around enhancing practice in the ambulance service; such as using specialist paramedics to attend to patients calling 999 with apparent minor injuries or illness following call-taker triage. But innovations by paramedics are increasingly being recognised in other arenas. This is partly because of the expectation that a paramedic can provide generalist care as an autonomous allied healthcare professional, for which several advantageous have been identified, including reduced conveyance to emergency departments, increased patient satisfaction with paramedic care, and efficiency benefits.[7]

The profession is regulated by the Health and Care Professions Council and the College of Paramedics act as the professional body. The College in particular supports the extended provision of clinical service, alongside increased educational/professional preparation.[8] The College's Subject Benchmark Statement (SBS) defines the expected competency from a paramedic graduate as "an autonomous practitioner who has the knowledge, skills and clinical expertise to assess, treat, diagnose, supply and administer medicines, manage, discharge and refer patients in a range of urgent, emergency, critical or out of hospital settings".[9] Newly qualified paramedics are expected to provide care across all practice areas, and the undergraduate curriculum endorsed by the College of Paramedics is designed to ensure that paramedics have effective core skills in their generalist roles. Some graduates go on to develop further skills, taking on Specialist, Advanced, and Consultant Paramedic roles (Table 1). 


\begin{tabular}{|c|c|c|}
\hline & Qualifications & Expected competencies \\
\hline Paramedic & $\begin{array}{l}\text { Requirements are a } \\
\text { certificate in higher } \\
\text { education with current } \\
\text { consultations made by the } \\
\text { registering body (HCPC) } \\
\text { and supported by the } \\
\text { College of Paramedics to } \\
\text { move to BSc(Hons) for } \\
\text { paramedic registration. } \\
\text { Current HE - Level } 5 \\
\text { Proposed HE - Level } 6\end{array}$ & $\begin{array}{l}\text { Individuals hoping to gain entry to } \\
\text { the paramedic register must } \\
\text { undertake an approved education } \\
\text { programme that demonstrates } \\
\text { achievement of the standards of } \\
\text { education and training and } \\
\text { standards of proficiency for } \\
\text { paramedics. There is no } \\
\text { requirement to follow the } \\
\text { undergraduate curriculum guidance } \\
\text { issued by the College of } \\
\text { Paramedics. }\end{array}$ \\
\hline Specialist Paramedic (SP)* & $\begin{array}{l}\text { Post-Registration and } \\
\text { PGDip in a subject } \\
\text { relevant to their practice, } \\
\text { typically critical care or } \\
\text { primary care. } \\
\text { HE - Level } 7\end{array}$ & $\begin{array}{l}\text { Their post-graduate education is } \\
\text { designed to develop knowledge, } \\
\text { abilities, and clinical expertise to an } \\
\text { enhanced level of practice, to allow } \\
\text { complex decision making, } \\
\text { competence and judgement in their } \\
\text { area of specialist practice. In the } \\
\text { workforce, SPs are used to provide } \\
\text { additional assessments to enable } \\
\text { diagnosis and treatment, which may } \\
\text { include the administration of } \\
\text { appropriate medications, including } \\
\text { those from patient group directions } \\
\text { (PGD). }\end{array}$ \\
\hline Advanced paramedic (AP) & $\begin{array}{l}\text { Post-Registration and } \\
\text { Masters level in a subject } \\
\text { relevant to their practice } \\
\mathrm{HE}-\text { Level } 7\end{array}$ & $\begin{array}{l}\text { Their knowledge base, clinical } \\
\text { responsibilities, and leadership are } \\
\text { most similar to those of advanced } \\
\text { clinical practitioners in other } \\
\text { professions, such as nursing, } \\
\text { pharmacy, and occupational } \\
\text { therapy. The ability to undertake } \\
\text { independent prescribing is aimed at } \\
\text { clinicians operating at this level and } \\
\text { above. A change is legislation is } \\
\text { being awaited to allow this to go } \\
\text { ahead following recommendation by } \\
\text { the Commission on Human } \\
\text { Medicines (CHM). }\end{array}$ \\
\hline Consultant paramedic & $\begin{array}{l}\text { Clinical/ } \\
\text { Professional - }\end{array}$ & $\begin{array}{l}\text { Capable of applying highly } \\
\text { developed theoretical and practical }\end{array}$ \\
\hline
\end{tabular}




\begin{tabular}{|l|l|l|}
\hline & $\begin{array}{l}\text { Doctorate } \\
\text { HE - Level } 8\end{array}$ & $\begin{array}{l}\text { knowledge over a wide range of } \\
\text { clinical, scientific, technical, and/or } \\
\text { management functions, which } \\
\text { include; clinical/professional } \\
\text { leadership; expert practice; policy } \\
\text { and service development, research } \\
\text { and evaluation; and education and } \\
\text { professional development }\end{array}$ \\
\hline
\end{tabular}

Table 1: Paramedic skill mix (adapted from reference [10]

*Other names for this group of paramedics have emerged through different healthcare providers; they include emergency care practitioner, community paramedic, enhanced paramedic, paramedic practitioner, and specialist practitioner. We adopt the term Specialist Paramedic, as advocated by the College of Paramedics.

The generalist skill mix of the modern day paramedic creates possibilities for them to work in a range of domains. Primary care is one domain in which additional capacity is desperately needed. Both specialist and advanced paramedics can work in primary care with differing degrees of autonomy, decision making, and treatment options within their scope of practice. Early review pointed to paramedics being deployed into primary care roles that included centralised telephone triage, on-scene acute care delivery, and intermediate community care support schemes [11]. However, there is now growing recognition that the generalist skills of the paramedic should be deployed into in-hours general practices.

\section{Current and future implementation}

The General Practice Forward View made a commitment to grow the wider workforce in general practice by a minimum of 5000 staff. However, there was no formal requirement that this workforce should include paramedics. Although absolute numbers remain small, between September 2016 and March 2017 the number of paramedics working in general practice doubled, increasing from 75 to 150.[12]

The NHS England GP Access Fund (formerly the Prime Minister's Challenge Fund) served as a platform to test, and to some degree, evaluate how paramedics can be deployed in primary care. The scheme was specifically introduced to help improve access to general practice and increase innovation in primary care. The first evaluation report highlighted at least four sites, among the 20 awarded funding, who piloted a range of models in primary care working with the ambulance service and paramedics.[13] In the South Kent Coast, specialist paramedics provided home visit support and dispensed some acute medications to community based patients. The service reportedly saved 720 GP appointments. In Workington, Specialist Paramedics were deployed into A\&E departments to determine whether patients could have been more appropriately treated in a Primary Care Centre. 
With a background as a paramedic, SPs are already experienced in assessing patients in their own home and SPs are also highly skilled at identifying care needs and directing these to other primary, secondary, or social services. A general practice SP should also be competent in assessing patients who present themselves to the surgery acutely unwell, including managing complaints such as chest pain, bouts of palpitation, abdominal pain, and breathlessness. One author (AR) currently works as an in-hours specialist paramedic in general practice, and here gives two anonymised case studies reflecting the type and context of care she provides (Table 2).

\begin{tabular}{|l|l|}
\hline Case 1 & $\begin{array}{l}\text { All home visits are directed to the Specialist Paramedic (SP). The SP is } \\
\text { managing an } 87 \text { year old lady with heart failure, atrial fibrillation, and } \\
\text { depression. She lives alone. The SP has built a relationship with the patient } \\
\text { through regular visits for INR monitoring and flu vaccination. However, over a } \\
\text { period of a few weeks the patient's breathing has deteriorated, alongside her } \\
\text { mobility and mental health. The SP conducts regular home visits, and these } \\
\text { include a physical assessment which on this occasion leads to the patient being } \\
\text { referred to the local day assessment unit and reviewed at the surgery multi- } \\
\text { agency group meeting (including social services, the community } \\
\text { physiotherapist, and the mental health team). The day assessment unit faxes } \\
\text { across her discharge summary and the SP liaises promptly with the patient's GP } \\
\text { to ensure that the action points have been addressed. This includes referral for } \\
\text { further scans and changes to her medications. The SP is in close } \\
\text { communication with social services and the wider multidisciplinary team, so } \\
\text { together they listen to the patient's wishes and the patient is able to move to a } \\
\text { local residential home, in the catchment area for the same GP surgery. The SP } \\
\text { visits this residential home weekly, which allows for continuity of care. }\end{array}$ \\
\hline $\begin{array}{l}\text { A } 64 \text { year old man attends the same-day rapid access clinic (RAC) in the } \\
\text { surgery. The RAC is run by a multidisciplinary team of a minor-illness nurse, a } \\
\text { SP, and a duty doctor. The patient complains of chest pain and is assessed by } \\
\text { the SP, who takes a comprehensive history and physical assessment and } \\
\text { promptly records an ECG. The patient is given aspirin and glyceryl trinitrate } \\
\text { spray. The SP rings the cardiac unit, and the patient is admitted to hospital. }\end{array}$ \\
\hline 2
\end{tabular}

\section{Table 2: Case studies of care provided by paramedics in general practice}

\section{Conclusions}

The NHS GP Forward View and the Primary Care Workforce Commission have both recommended the development of a multidisciplinary primary workforce that includes general practice-based paramedics. The NHS has already had a positive public response to proposals to introduce independent prescribing by paramedics, facilitating new roles in primary care [14]. However, the empirical evidence base to support these roles is currently weak, and implementation is largely based on innovative case studies. The current opportunities for employment in NHS general practices still requires careful evaluation for context specific clinical 
outcomes, value, and satisfaction.[15] Empirical data from other countries e.g. North America, may not be directly transferable to England due to contrasting healthcare systems. There will also need to be a significant expansion in the overall number of paramedics for there to be real impact on NHS primary care. This potential expansion would need to be considered in the context of any impact on current ambulance services.. Nevertheless, the scene is set for the general practice paramedic, a setting that is desperate for extra capacity, and integrated multidisciplinary teams of the future..

Funding: KM receives funding from the NIHR SPCR Evidence Synthesis Working Group to colead work on primary care service redesign. No other specific funding was received.

Disclaimer: The views expressed in this commentary represent the views of the authors and not necessarily anyone else mentioned in this article, the host institution, the NHS, the NIHR, or the Department of Health.

Contributorship statement: KM conceived the idea for this essay. All authors contributed to the final manuscript. KM acts as guarantor.

Ethical approval: None.

Competing interests: KM, GE and MC declare no competing interests. AR is a paramedic working in an NHS general practice.

Acknowledgements: We thank Jeffrey Aronson for comments on an earlier draft. 


\section{$\underline{\text { References }}$}

1 Baird B, Charles A, Honeyman M, et al. Understanding pressures in general practice. The King's Fund. 2016.https://www.kingsfund.org.uk/publications/pressures-in-general-practice (accessed 10 Apr 2017).

$\underline{2}$ Majeed A. Shortage of general practitioners in the NHS. BMJ 2017;358:j3191.

3 Practice G. General practice » General Practice Forward View. https://www.england.nhs.uk/gp/gpfv/ (accessed 8 Dec 2016).

4 Roland M. The Future of Primary Care: Creating teams for tomorrow (Report from the Primary Care Workforce Commission). Health Education England.

2015.https://www.hee.nhs.uk/our-work/hospitals-primary-community-care/primarycommunity-care/primary-care-workforce-commission (accessed 10 Apr 2017).

5 Nelson $\mathrm{P}$, Martindale A-M, McBride A, et al. Skill-mix change and the general practice workforce challenge. Br J Gen Pract 2018;68:66-7.

6 Skill mix case studies | The BMA. 2015.https://www.bma.org.uk/advice/employment/gppractices/quality-first/working-at-scale/skill-mix-case-study (accessed 13 Mar 2018).

7 M Mason S, O'Keeffe C, Coleman P, et al. Effectiveness of emergency care practitioners working within existing emergency service models of care. Emerg Med J 2007;24:239-43.

$8 \quad$ Lovegrove M, Davis J. Paramedic Evidence Based Education Project (PEEP) End of study report. Allied Health Solutions and Buckinghamshire New University 2013.

9 The Quality Assurance Agency for Higher Education (QAA). The Quality Assurance Agency for Higher Education (QAA). Published Online First: 1 January 2014.http://www.qaa.ac.uk/ (accessed 18 Dec 2017).

10 Post-Reg Career Framework | Professional Development. https://www.collegeofparamedics.co.uk/publications/post-reg-career-framework (accessed 18 Dec 2017).

11 Ball L. Setting the scene for the paramedic in primary care: a review of the literature. Emerg Med J 2005;22:896-900.

12 Digital N. General and Personal Medical Services, England As at 31 March 2017, Experimental statistics. https://digital.nhs.uk/catalogue/PUB30044 (accessed 20 Dec 2017).

13 England N. NHS England » GP Access Fund. 2017.https://www.england.nhs.uk/gp/gpfv/redesign/improving-access/gp-access-fund/ (accessed 13 Oct 2017).

14 England N. NHS England » Proposals to introduce independent prescribing by Paramedics. 2016.https://www.england.nhs.uk/ahp/med-project/paramedics/ (accessed 20 Dec 2017).

15 Eaton G, Catterall M, Mahtani KR. The evolving role of Paramedics - a NICE problem to have? J Health Serv Res Policy 2017;(submitted - JHSRP-17-210.R1). 
